\title{
Ampliando Perspectivas para a Análise da Pesquisa sobre Aprendizagem Organizacional: uma Tréplica
}

\author{
Elizabeth Loiola \\ Antonio Virgilio Bittencourt Bastos
}

Os comentários, a título de réplica ao trabalho sobre a produção acadêmica em aprendizagem organizacional no Brasil, certamente introduzem elementos novos que ampliam o foco e reafirmam as discussões que são centrais para todos os que se dedicam à investigação de tão atual e instigante questão.

Em primeiro lugar, cabe assinalar que os comentaristas destacam, com precisão, os pontos cruciais que emergem como resultado do trabalho inicial. No entanto, mais do que apontar as contribuições advindas de um estudo que tem, reconhecemos, um recorte que impõe limites naturais de abrangência do campo - na sua dimensão temporal e de extensão do material analisado - a réplica recupera duas discussões fundamentais e, para elas, traz contribuições significativas. Cumpre, portanto, o papel de fazer avançar o debate e de abrir novas veredas para a investigação.

No presente texto vamos concentrar-nos nos dois pontos eleitos como focos prioritários da análise e da discussão dos comentaristas.

O primeiro refere-se à tradição de mapeamento do campo, envolvendo duas grandes vertentes - os estudos sobre aprendizagem organizacional e sobre organizações que aprendem. Como bem salientam, trata-se de uma configuração que surge na literatura anglo-saxônica e que cumpre o papel de organizar duas trajetórias bastante diferenciadas de problematização, investigação e intervenção em face do fenômeno da aprendizagem organizacional.

O segundo aspecto reporta-se a uma questão metodológica mais circunscrita, mas que possui estreita relação com problemas conceituais sobre a natureza ontológica do fenômeno que chamamos de aprendizagem organizacional: o caráter mais, ou menos, processual dos delineamentos de investigação utilizados.

\section{Como Organizar a Dispersa literatura Existente sobre Aprendizagem Organizacional?}

A dispersão, a pulverização conceitual e a diversidade de perspectivas teóricas 
para apreender um objeto não são marcas distintivas dos estudos sobre aprendizagem organizacional. Pelo contrário, tais traços parecem caracterizar não só o campo dos estudos organizacionais como a própria produção científica nas ciências humanas e sociais. São diferenças que nascem de pressupostos conflitantes sobre a natureza humana, sobre a concepção de prática científica, sobre o compromisso com a realidade social, como classicamente analisam Burrell e Morgan (1979). Esse quadro ganha contornos mais sérios, quando se constatam a reduzida interlocução de perspectivas distintas e a forte carga valorativa com que pontos de vista divergentes são tratados por seus oponentes, dificultando consensos mínimos necessários ao fazer cumulativo da ciência.

Diante da diversidade que marca esse território, qualquer tentativa de mapeálo implica escolhas ou decisões que revelam perspectivas ou interesses do estudioso. Assim, também não é surpreendente que possamos ter múltiplas dimensões para organizar a natural dispersão observada nos estudos sobre aprendizagem organizacional. Prange (2001), por exemplo, postula que a polissemia do campo pode ser interpretada como indicador de progressão teórica, desde quando se abandone certa orientação metateórica e se abrace uma visão antipositivista, a qual pode levar à percepção de que é mesmo normal apresentar perspectivas divergentes, considerando-se que não há um mundo objetivo a ser descoberto. Argyris e Schön (1996) acreditam que a persistência de problemas conceituais não resolvidos no campo de aprendizagem organizacional se vincula à bifurcação da comunidade de interessados entre pesquisadores acadêmicos e práticos. É tal distinção que leva Tsang (1997) a reforçar a existência de duas grandes vertentes do campo, enfatizando as diferenças entre uma perspectiva mais descritiva e outra mais prescritiva. Apenas a título de recuperar a distinção central entre essas duas vertentes, vale destacar que o autor fixa como elemento distintivo central a ênfase na descrição ou na prescrição. Enquanto a aprendizagem organizacional (AO) se interessaria pela descrição de como a organização aprende, focalizando as habilidades e processos de construção e utilização do conhecimento, a vertente organizações que aprendem (OA) se voltaria para desenvolver ferramentas metodológicas para diagnóstico e avaliação, a partir do que seria possível fazer prescrições sobre o que uma organização deve fazer para aprender.

A separação entre as vertentes aprendizagem organizacional versus organizações que aprendem é, devemos reconhecer, apenas uma possível sistematização encontrada para agrupar perspectivas distintas de conceber e investigar os processos de aprendizagem organizacional. Embora tragam embutidas as dificuldades inerentes a qualquer sistema dicotômico para lidar com a realidade fluida e complexa, as duas vertentes nascem em função de uma tensão que caracteriza fortemente o campo dos estudos organizacionais: a busca de 
conhecimento versus a necessidade de intervenção em face de problemas concretos. Essa tensão se faz presente em praticamente todos os domínios e tópicos da área, não sendo privilégio daquele sobre o qual nos detemos no presente momento. Como bem caracterizam diversos autores, essas duas vertentes partem de concepções muito distintas do fenômeno e, em decorrência, delineiam as suas pesquisas de forma também assaz diferente, como tivemos oportunidade de caracterizar no artigo, a partir das referências teóricas que embasam o estudo.

O que a análise da produção científica nacional revelou, talvez por limites do instrumento utilizado para fazer os julgamentos, é que tal distinção não se revela tão visível como esperávamos a partir do exame da literatura internacional. As diferenças, no entanto, existem. Elas podem ser menores do que o esperado pelo próprio recorte do estudo que restringiu a análise à produção acadêmica, excluindo, a priori, aquela produção direcionada mais claramente para o segmento gerencial e publicada em livros ou revistas de cunho menos acadêmico. Neste sentido, novos estudos poderiam ampliar o leque de periódicos, com amostras daqueles prioritariamente voltados para gestores. Possivelmente, teríamos um quadro distinto daquele descrito no artigo inicial, sendo elevada a probabilidade de que a vertente mais prescritiva e normativa aparecesse de forma mais nítida. É tal probabilidade que nos levou a ser cautelosos na discussão dos achados, não descartando a tradição de divisão do campo nas duas vertentes citadas.

Os comentaristas, no entanto, trazem contribuição muita rica ao proporem seis grandes focos como eixos para distinguir diferentes perspectivas no estudo sobre aprendizagem organizacional. Embora se detenham em três desses focos, percebese tratar-se de sistema que pode revelar-se bastante heurístico para explorar o campo. Como os autores reconhecem, tais focos mostram singularidades, mas há, entre eles, grande conectividade. Não é preciso muito esforço para identificar, por exemplo, que trabalhos de Karl Weick estão incluídos nos focos cultura e gestão de conhecimento. Da mesma forma, o clássico trabalho de Argyris e Schön encontra-se nos focos socialização da aprendizagem organizacional e cultura; ou seja, esses múltiplos focos, conquanto possam trazer aspectos distintivos na forma de conceber e investigar a aprendizagem organizacional, não são excludentes e certamente podem ser combinados.

Cabe-nos reconhecer, neste momento, enquanto aguardamos a publicação do trabalho completo, que a proposta de Claudia Simone Antonello pode vir a constituir uma grade analítica mais sofisticada para captar a diversidade que caracteriza o campo do que as duas vertentes extraídas da literatura internacional sobre o tema. Ela, certamente, incorpora maior variabilidade e não se restringe a um modelo tudo-nada (daí, maior flexibilidade, como afirmam os comentaristas). 
Ao se trabalhar com um sistema classificatório apoiado em categorias temáticas, temos apropriadamente um painel mais detalhado da diversidade com que pesquisadores abordam a questão, vinculando-a a outros fenômenos importantes para a compreensão da vida organizacional. Ao aproximar aprendizagem de cultura, de gestão do conhecimento ou de socialização, podemos identificar diferenças e semelhanças no tratamento do conceito, no posicionamento sobre quanto deste processo é individual ou coletivo, assim como nas estratégias metodológicas mais apropriadas. Com esta nova grade, várias distinções se diluem, é verdade. A tensão que está subjacente à dimensão que separa a $\mathrm{AO}$ da OA é uma delas, podendo-se encontrar aportes mais descritivos e mais prescritivos em todas as categorias. Não podemos, porém, tratar os dois quadros de referência de apreensão deste fragmento da realidade como excludentes. Eles, seguramente, atendem a objetivos e a perspectivas de quem olha o campo; assim cada grade destaca alguns aspectos e esconde outros; lança luz sobre uma face e deixa outra na penumbra.

É conhecida, por exemplo, a tensão que caracteriza o entendimento dos níveis em que o fenômeno da aprendizagem pode ocorrer. Tal tensão vincula-se ao núcleo central das discussões sobre a natureza do que chamamos aprendizagem organizacional - e até que ponto o uso de tal termo não é apenas metafórico. Relaciona-se, também, com as discussões sobre reificação e antropomorfização da organização, com implicações importantes sobre a teoria e as estratégias de investigação (Døving, 1996). Embora tal questão seja tão relevante, ela é apenas um dos elementos distintivos entre $\mathrm{AO}$ e OA; parece-nos, também, que tal dimensão não se constitui eixo significativo para diferenciar as seis perspectivas identificadas e caracterizadas por Antonello. Neste sentido, poder-se-ia pensar em nova rede de categorias, que diferenciassem abordagens e pesquisa nesta dimensão tão importante para a conceituação do problema. Com esse exemplo, queremos apenas ressaltar que os matizes grades teórico-conceituais são sempre limitadas e refletem escolhas pessoais para capturar as nuances e sutilezas desse território rico e multifacetado, que envolve um complexo processo individual, que é, por natureza, embutido em processos sociais que articulam pessoas em grupos e em organizações.

Vale reconhecer, contudo, a contribuição apresentada pelos comentaristas, ao fornecerem um quadro conceitual novo para explorar o campo dos estudos sobre aprendizagem organizacional. A sua aplicação para caracterizar a produção científica pode assegurar insights importantes para uma contemplação crítica dos limites e potencialidades das diferentes perspectivas. Trata-se, por conseguinte, de uma nova vereda a ser aberta na análise da produção científica sobre esse tópico. 


\section{Sobre Possibilidades de Investigação do Fenômeno}

O segundo ponto a merecer atenção especial dos comentaristas, reporta-se à questão metodológica e, mais especificamente, ao uso de delineamentos longitudinais que abordem microprocessos de aprendizagem.

Aqui, cremos que os comentaristas partilham o mesmo entendimento e as mesmas preocupações nossas, quando verificamos o reduzido peso de trabalhos longitudinais na pesquisa sobre aprendizagem organizacional. Não se trata, evidentemente, de atribuir valor especial a esse tipo de estudo ou de considerá-lo superior aos demais delineamentos de pesquisa. Neste particular, acreditamos que as decisões metodológicas se subordinam, necessariamente, aos objetivos e à natureza do problema investigado; a coerência entre pergunta e modo de responder a ela se torna o critério essencial de avaliação.

Os pesquisadores em organizações bem sabem as dificuldades que cercam a realização de qualquer pesquisa; tais dificuldades se ampliam quando implicam permanência mais demorada da equipe de pesquisa na empresa. A própria pressão por produtividade não pode ser afastada como um dos fatores que levam a estudos que reduzem a sua extensão temporal. Essas dificuldades, possivelmente, explicam o reduzido número de pesquisas longitudinais, embora seja amplamente difundida a crença ou a visão de que os fenômenos organizacionais são, em essência, processuais, dinâmicos ou fluidos.

No caso da pesquisa sobre aprendizagem organizacional, no entanto, esse problema se revela agudo pela própria natureza do fenômeno em tela. No nível individual, aprendizagem é processo inferido a partir de mudanças, quer no comportamento, quer nas estruturas cognitivas, quer nas reações afetivas em face de situações. Aprender é quase sinônimo de mudar, reestruturar, modificar crenças, idéias, pensamentos, cognições, formas de agir e lidar com a realidade. Fenômeno classicamente estudado pela Psicologia, a investigação de aprendizagem envolve estratégia metodológica que incorpore a dimensão temporal como essencial para capturar ou descrever o próprio fenômeno. Essa dimensão também nos parece crítica, quando passamos a tratar da aprendizagem no nível organizacional. Não é sem sentido a força com que aprendizagem se vincula a conceitos de mudança e inovação, como bem ficou explícito no artigo inicial.

Por outro lado, tal questão, junto com o eixo descritivo-prescritivo, parece central na configuração das vertentes $\mathrm{AO}$ e $\mathrm{OA}$. A preocupação com processo de aprendizagem deveria conduzir a estudos que explorassem o fenômeno ao longo de certo período de tempo; a caracterização das organizações que aprendem, por 
seu turno, poderia ser adequadamente estudada por meio de delineamentos que prescindem desta perspectiva temporal. Daí termos dado destaque especial à carência de estudos longitudinais, apesar do peso expressivo de estudos localizados na vertente $\mathrm{AO}$, logo mais direcionados para apreender processos e, portanto, incorporar uma perspectiva temporal na coleta e análise dos dados. Em oposição, o traço mais distintivo da segunda vertente seria os estudos de corte transversal, já que a contribuição central seria a de caracterizar organizações que aprendem, diferenciando-as daquelas que não aprendem e explorando condições propiciadoras ou não desses processos. Os dados obtidos no levantamento não apontaram uma tendência nítida neste particular, o que se deve ao reduzido número de estudos com recorte longitudinal. Eles são poucos, mas existem.

A contribuição oferecida pelos comentaristas neste item em particular, é bem reveladora do dinamismo com que se move o campo dos estudos sobre aprendizagem organizacional no Brasil. Foram apresentados dois trabalhos como exemplos de pesquisas que estão voltadas para o estudo de microprocessos de aprendizagem e que incorporam uma perspectiva longitudinal. Nessas pesquisas, pode-se vislumbrar novos caminhos que, também no nosso entendimento, articulam de forma mais apropriada a natureza do fenômeno da aprendizagem - individual e organizacional - à estratégia para investigá-lo.

Os exemplos citados, por outro lado, deixam explícito mais um limite do estudo inicial de caracterização do campo: não se abarcou a produção de teses e dissertações de mestrado que não tiveram, ainda, a sua publicação em veículo de divulgação mais amplo, como periódicos e anais. O exame desta produção poderá trazer elementos novos para a compreensão da dinâmica e da evolução do campo e, especialmente, identificar tendências futuras; ou seja, a apresentação dos dois trabalhos, um concluído e outro em fase de conclusão, pode indicar-nos a possível emergência de transições neste campo de estudo, que poderão vir a alterar algumas dimensões importantes da forma como a aprendizagem organizacional virá a ser estudada em futuro próximo.

Um desafio que se coloca para a pesquisa na área, ainda não contemplado em nível apropriado, quer no Brasil, quer no exterior, refere-se ao tratamento simultâneo dos diferentes possíveis níveis de análise do fenômeno aprendizagem organizacional. Se aprendizagem é fenômeno individual, como se dá a transformação do conhecimento individual em conhecimento organizacional? O avanço de uma perspectiva construtivista coloca outras questões, como bem aponta Resnik (1996): como as pessoas podem conhecer uma mesma coisa, se cada uma está construindo seu conhecimento independentemente? Como os grupos sociais podem coordenar suas ações se cada indivíduo pensa de forma diferente sobre a mesma coisa? Tais questões revelam como o domínio da aprendizagem 
organizacional requer a contribuição de múltiplos campos disciplinares e ainda se depara com extensa agenda de pesquisa por cumprir.

Em síntese, a análise e contribuições dos comentaristas reafirmam a importância de se tomar a produção de conhecimento científico como objeto legítimo de estudo. Análises, mesmo descritivas como a que apresentamos no artigo inicial, ensejam reflexões críticas e têm impacto sobre os rumos do conhecimento produzido. Espaços, como este criado pela RAC, ampliam o diálogo entre pesquisadores de uma mesma temática e, especialmente, podem fomentar uma consciência do nível em que a nossa produção científica está respondendo aos múltiplos desafios postos por este domínio da realidade organizacional. Assim, resta-nos reconhecer que os comentários sobre o trabalho apresentado trazem contribuições que justificam o título desta tréplica; a partir deles, pode-se pensar em novos e mais refinados modelos analíticos da produção científica sobre aprendizagem organizacional.

\section{Referências Bibliográficas}

ARGYRIS, C.;

SCHÖN, D. A.

Organizational learning: a theory of action perspective. Reading, MA: Addison-Wesley, 1978.

BURRELL, G.;

MORGAN, G.

Sociological paradigms and organizational analysis. London: Heinemann, 1979.

DØVING, E.

In the image of man: organizational action, competence and learning. London: Sage Publications, 1996.

PRANGE, C.

Aprendizagem organizacional: desesperadamente em busca de teoria? In: EASTERBY-SMITH, M.; BURGOYNE, J.; ARAUJO, L. (Orgs.). Aprendizagem organizacional e organização de aprendizagem: desenvolvimento na teoria e na prática. São Paulo: Atlas, 2001.

RESNIK, L. B.

Shared cognition: thinking as social practice. In: RESNIK, L. B.; LEVINE, J. M.; TEASLEY, S. D. Perspectives on socially shared cognition. Washington, DC: [s.n.], 1996.

TSANG, E. W. K.

Organizational learning and the learning organization: a dichotomy between descriptive and prescriptive research. Human Relations, v. 50, n. 1, p. 73-89, 1997. 